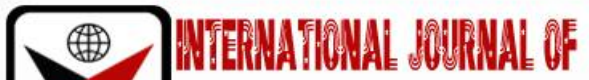

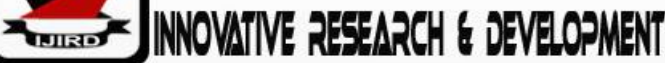

ISSN 2278 - 0211 (Online)

\section{Assessing Climate Change Trends within the Sondu Miriu River Basin and Impacts on Hydropower Generation, Kenya}

\author{
Willis Owino Ochieng \\ Ph.D. Student, Institute for Climate Change and Adaptation, University of Nairobi, Kenya \\ Christopher Oludhe \\ Senior Lecturer, Institute for Climate Change and Adaptation, University of Nairobi, Kenya \\ Simeon Dulo \\ Senior Lecturer, Institute for Climate Change and Adaptation, University of Nairobi, Kenya
}

\begin{abstract}
:
Climate change is the expected outcome of increases in atmospheric concentrations of "greenhouse" gases resulting from human activities. Energy has been identified as one of those sectors that contribute more towards GHGs emissions while renewable energy technologies have the potential to mitigate GHGs emissions. Among all the renewable energy technologies being utilized, hydropower stands out to be the most stable and proven technology over time compared to the others. Despite hydropower having the potential to mitigate climate change impacts and support some adaptation strategies, it is also likely to be impacted on by climate change.

This paper, presents findings of the climate change trends within the Sondu Miriu River basin and evaluating the impacts on the hydropower generation. It involves downscaling of the global scale climate change scenarios to the local scale to be able to determine the existing and projected trends.

The analysis has demonstrated that the rainfall received in the last thirty years have displayed upward trends. This confirms the climate change scenarios that have been projected by the IPCC for this region. The impact of increased rainfall has impacted positively on average hydropower energy output that has indicated upward trends for the two existing hydropower plants.
\end{abstract}

Keywords: Climate change, trends, hydropower generation, impacts

\section{Introduction}

Climate change is the expected outcome of increases in atmospheric concentrations of "greenhouse" gases resulting from human activities. Many greenhouse gases, including carbon dioxide $\left(\mathrm{CO}_{2}\right)$, occur naturally and keep the earth warm by trapping heat in the atmosphere. However, since the Industrial Revolution, anthropogenic sources of $\mathrm{CO}_{2}$ have added greatly to the atmospheric concentrations, and in particular, transportation and the burning of fossil fuels for electricity generation are frequently cited as major sources. Other man-made greenhouse gases, such as Chlorofluorocarbons (CFCs), are believed to intensify the process. Enhanced levels of greenhouse gas concentrations are predicted to cause a significant rise in temperature over the next century. The current scientific consensus is that under present rates of economic and population growth global mean temperatures will rise by $3^{\circ} \mathrm{C}$ by the end of the next century. This is expected to be accompanied by increases in global precipitation levels of 15\% (Kumar et al 2011).

Changes in the quantity and timing of river runoff, together with increased reservoir evaporation will have a number of effects on the production of hydroelectric power. These include impacts upon system operation, financial effects and impacts on other energy sectors (Harrison et al, 1998).

The knowledge of climate change scenarios at basin scale can aid sustainable development planning which addresses the issues of climate change impacts mitigation and adaptation. In most cases climate change scenarios are only available at global and regional scales. It may not be easy to have sustainable development plans in Sondu Miriu Basin that integrates climate change 
without the knowledge of climate change scenarios. This paper aims at assessing climate change scenarios within the Sondu Miriu River basin.

Adaptation to climate change is an essential component of sustainable development (Moomaw et al., 2011). Adaptation can be either anticipatory or reactive to an altered climate. Some renewable energy technologies may assist in adapting to climate change, and are usually anticipatory in nature (Klein et al., 2007). Dams (used for hydropower) may also be important in managing the impacts of droughts and floods, which are projected to increase with climate change (WCD, 2000). hydropower.

The objective of this study is to assess climate change scenarios within the Sondu Miriu River basin and their impacts on

\section{Area of Study}

Sondu Miriu river basin has been selected as a pilot basin due to its potential for hydropower development. The basin currently has got two hydropower plants running. The basin supports various socioeconomic activities within the basin and in the neighbouring basins. It is, therefore, of interest to study the interaction between hydropower development and socioeconomic and environmental activities in this area.

Sondu-Miriu river basin is located in the Western part of Kenya within the Lake Victoria Basin as illustrated in figure 1. The basin currently has got two hydropower schemes, namely Sondu Miriu and Sangoro, which draw water from the Sondu-Miriu River for hydroelectric power generation into the national electricity grid.

The Sondu-Miriu River basin is located at latitude $0^{\circ} 17^{\prime} \mathrm{S}$ and $0^{\circ} 53^{\prime} \mathrm{S}$, longitude $34^{\circ} 45^{\prime} \mathrm{E}$ and $35^{\circ} 45^{\prime} \mathrm{E}$. It forms the fourth largest basin of Kenyan rivers that drain into Lake Victoria, covering an area of 3,500 km² (Masese et al., 2012). The main tributaries of the river are the Kapsonoi and Yunith. The river originates from the Mau Forest Complex, an expansive water tower in Kenya. The Sondu-Miriu River catchment is characterized by diverse land use types and developments including forestry, large-scale and smallscale agriculture, urban and sub-urban settlements, agro-based industries and hydroelectric power generation. Because of the combined effects of these human activities, and the increase in their scale and intensity over the years, they impose multiple threats to water quality, aquatic biodiversity and general ecology of the river. Evidently, the water quality status in the Sondu-Miriu River has recorded increasing rates of sedimentation over the years (Masese et al., 2012). 


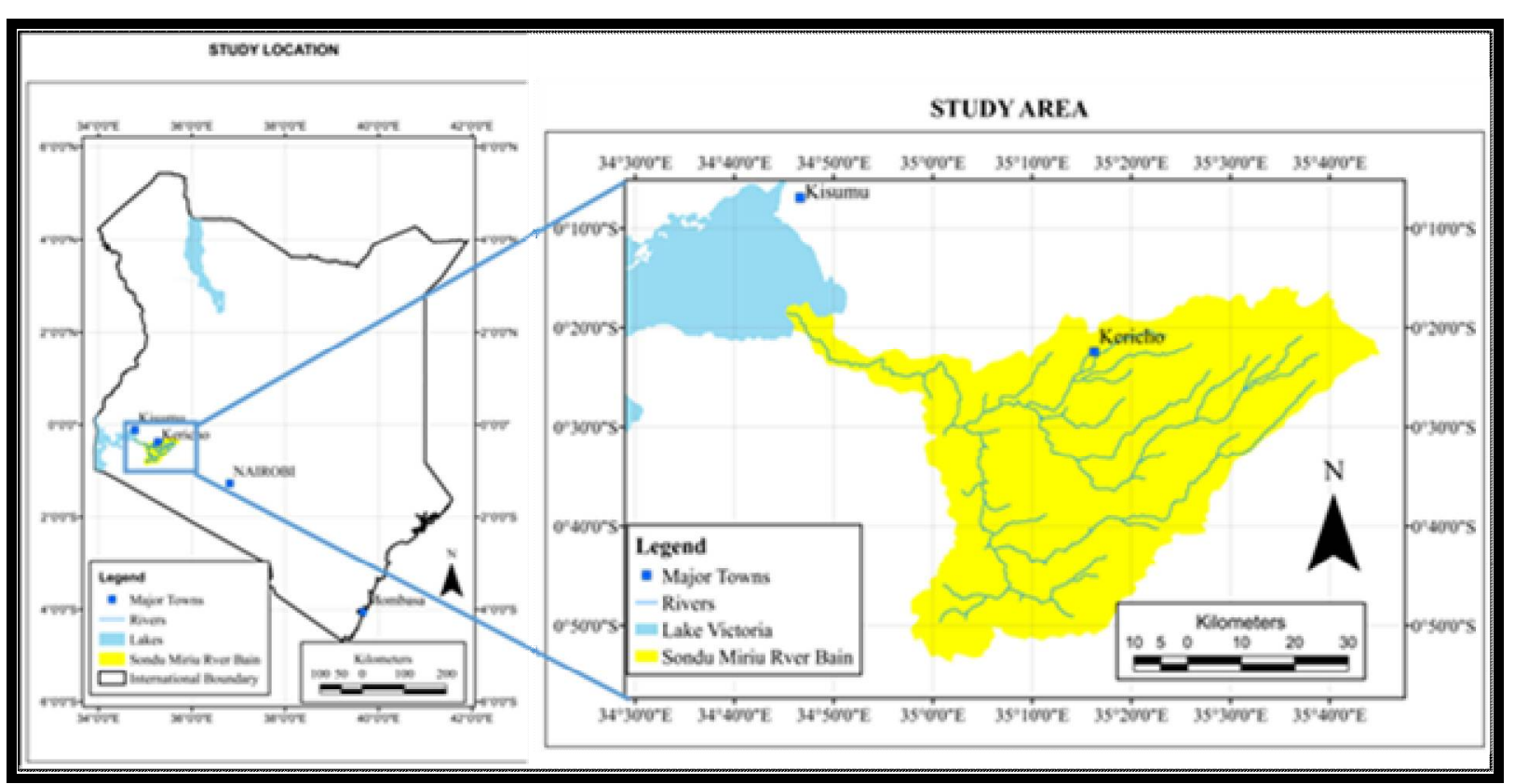

Figure 1: Map showing the position of the Study Area

\section{Literature Review}

\subsection{Climate Change}

Globally, climate change has got a lot of influence on precipitation and temperature. The two parameters determine availability of water resources for various competing uses including hydropower. Rainfall is considered the main river flow source for hydropower generation and other competing uses. In Kenya temperatures have been on increasing trends based on the long term observations. The minimum and maximum temperatures have risen generally by $0.7^{\circ} \mathrm{C}$ to $2.0^{\circ} \mathrm{C}$ and $0.2^{\circ} \mathrm{C}$ to $1.3^{\circ} \mathrm{C}$ respectively across the country $(\mathrm{GoK}, 2010)$.

\subsection{Climate Modeling}

The only known available primary tools for investigations on how the climate system responds to various forcings are climate models. These climate models also provide the possibility of producing climate predictions not only on seasonal and dekadal time scale but also predictions for the next century and beyond (Flato et al., 2013). Both the simple energy balance models and the complex earth system models require state-of-the-art computing capabilities with high performance. Scientific question being addressed will directly determine the choice of model to be applied in the research (Held, 2005; Collins et al., 2006). These applications include simulations of palaeoclimate, process studies and sensitivity analysis for characterization and physical understanding, short term prediction of climate change and variability based on both seasonal and dekadal time scales. This facilitates the future climate change projections in the next century and downscaling these projections for the purpose of providing more details at both the regional and local time scales. When larger ensembles or longer integration are required, it is possible to use simplified models which have reduced complexities or spatial resolution due to computational costs that may be involved (Flato et al., 2013).

Models are usually classified based on their components functions represented interactively. There is always a representation of physical characteristics of both the ocean and sea ice in the majority of climate studies. The ice sheet, dynamic vegetation and terrestrial and marine carbon cycles components are regularly included leading to Earth system model (Goose et al., 2010).

The models can also be differentiated based on the complexity of the processes that are included in them. On one hand, the GCMs usually account for the most important properties in the system at possibly the highest and affordable resolution. The aim of introducing the General Circulation model was the simulations of the three dimensional structure of currents and winds in the most realistic way. The GCMs have been classically divided into two groups. These groups are Atmospheric General Circulation Models (AGCMs) and Ocean General Circulation Models (OGCMs). By the use of interactive atmospheric and ocean components, Atmospheric and Ocean Circulation model (AOGCM) and the wider Coupled General Circulation Model (CGCM) are used generally for the purpose of climate studies (Goose et al., 2010).

In cases where biogeochemical feedbacks are not critical, Atmospheric and Ocean General Circulation Models (AOGCMs) continue to be used extensively. In some cases they are run at high resolution in particular for the seasonal and dekadal climate prediction applications. The primary function for these models is to provide an understanding of the physical components dynamics 
of the climate system including the ocean, sea ice, land and atmosphere as well as the provision of the projections which are based on the future greenhouse gas (GHG) and aerosol forcings. For the process studies or even applications focusing on a particular region, AOGCMs are usually used with high or variable resolution (IPCC, 2013).

On the other hand there are simple climate models. One example of the simple models with highly simplified version of representation of the climate system dynamics is the Energy Balance Models (EBMs). This involves averaging of the variables over large regions and in some cases the averaging can even be done to cover the whole Earth. Through the parameterization many processes are usually not represented or even accounted for. This has resulted in the EBMs having a smaller number of degree of freedom (Goose et al., 2010).

The changes in climate system are usually estimated by the Energy balance models from the analysis carried out on the Earth's energy budget. In their simplest forms these models usually exclude explicit spatial dimension and only provide variable with globally averaged values computed. These models are therefore called zero dimensional EBMs (Budyko, 1969 and Sellar 1969).

Zero dimensional EBMs may be extended in some cases to include one or two horizontal dimensions. This can be done to take into consideration the geographical distribution of the Earth's surface temperature.

The box models usually represent very large areas and sometimes even the whole component of the system. The representation is always by an average describing the mean over the whole "box" and therefore possessing clear similarities with the EBMs. The interactions taking place between the various components of the climate system are usually parameterized. This parameterization is always done as a function of the different boxes characteristics. These boxes are usually defined based on the model purpose. Some of these box models include components for the land and ocean surface layers, atmosphere and the ocean which helps in differentiating between the two hemispheres. The others box models further provide additional components that helps in describing the carbon cycle and therefore having boxes that correspond to the various reservoirs (Goose et al., 2010).

\subsection{Components of Climate Models}

The climate system consists of five major components. The system is an interactive system whose components include land surface, cryosphere, hydrosphere and diosphere. Various external forcing mechanisms influence the climate system components. The sun is the most significant of these forcings. The direct human activities effect on the climate system is also considered as a significant forcing (Goose et al., 2010).

\subsubsection{Coupling between the Components - Earth System Models}

The Earth Systems Models (ESMs) are currently considered as the state of the art models. These models provide for expansion on the AOGCMs whereby various biogeochemical cycles can be adequately represented similar to those for the carbon cycle, sulphur cycle or ozone (Flato, 2011). The most available comprehensive tools for simulating how both the past and future climate system responds to external forcing are provided by these Earth Systems Models. In these simulations, biogeochemical feedbacks play a very important role (IPCC, 2013).

The Earth Models of Intermediate Complexity (EMICs) are usually located between two extremes. The basis for the EMICs, compared to the EBMs, are more complex and offers a comprehensive representation of the climate system. Despite being complex, the EMICs consist of simplified and parameterized processes. These processes are usually clearly accounted for in the GCMs. The broadest category of the models are formed by the EMICs. Some of them are comprehensively similar to the simple models even though others are being considered as marginally degraded GCMs (Goosse et al., 2010).

EMICs attempt to take account of appropriate Earth system components. This is regularly done in such a way that the resolution is lower than other models or assuming an ideal situation. These models are only applicable to definite scientific questions. These questions may require an understanding of climate responses that are based on millennial time scale or even an exploration of sensitivities that involve longer integrations of the model or to some extent require large ensembles (Claussen et al., 2002 and Petoukhov et al., 2005). The components of the Earth system that are not yet incorporated in all the ESMs are usually included in this class of models. A good example is the ice sheets component. This class of models has been advancing continuously in terms of resolution and complexity as a result of the rising computing power (IPCC, 2013).

Global climate models are capable of directly providing climate information at regional scale. However, the only disadvantage they have is always too low horizontal resolution that is not able to resolve key important features at regional scale. The AGCMs that are always of high resolution together with global models that are of variable resolutions and both statistical and dynamic downscaling such as regional climate modelling are usually applied to complement AOGCMs as well as for the generation of the region specific climate information (IPCC, 2013).

Stand-alone AGCMs operating at advanced resolution in comparison to the AOGCMs usually provide complementary climate information at regional scale which at times is referred to as 'global downscaling' (IPCC, 2013). Several benefits have been associated with high resolution AGCMs. These benefits include improvement of the regional precipitation (Kusumoki et al., 2011; Zhao et al., 2009) and blocking (Matsueda et al., 2009, 2010). As the interactions with the oceans are not simulated by the AGCMs, their capacity to capture high resolution phenomena is restricted. The quality of the physical parameterizations involved usually affects the performance of the AGCMs just as in lower resolution models (Mizuta et al., 2012; Lin et al., 2012; Zhao et al., 2012).

Several climate models have participated in the Coupled Model Intercomparison Projects. These models consequently comprise a set of climate models experiments that are coordinated, very consistent and progressively well documented. By evaluation, the Coupled Model Intercomparison Project Phase 5 (CMIP5) are now only being evaluated with less published literature available (IPCC, 2013). 
Comparing the temperature and precipitation seasonal cycles in the CMIP3 and CMIP5 for various regions indicates a better simulation of temperature compared to precipitation. This is particularly when having a consideration for phase and amplitude of the seasonal cycle. Comparing the majority of the models individually with the average of the multi-model reveal that the result for the multi-model average is much closer to the observations. Comparing CMIP5 and CMIP3 ensembles in most of the regions indicate that the systematic variance between them is usually small. South America and South Asia regions indicate evidence of good progress especially during the rainy season. In some cases the range of observational estimates and model outputs are similar in magnitude particularly during winter in the Europe and Mediterranean region (IPCC, 2013).

\subsection{Downscaling Climate Information to Regional Level}

The necessity for climate change information is one of the fundamental issues within the discussions of climate change. This is especially happening at both the regional and local scale. This particular information is very critical for the evaluation of the impacts of climate change on the human livelihood and natural systems including coming up with suitable adaptation strategies at both the nationally and locally (Giorgi et al., 2009).

The regional climate downscaling (RCD) through the application of both dynamical and statistical tools have been increasingly used in addressing most of the issues relating to climate change. Presently RCD has become a significant methodology for research in the area of climate change (Huntingford and Gash, 2005). There have been underutilization of the RCD based products. It is believed that the main reason for this underutilization can be attributed to lack of coordinated framework for evaluating RCD based techniques for the production of ensemble projections which are of sufficient quality that allows for characterization of the uncertainties underlying the projections for climate change at the regional level. These coordinated frameworks exist for the global models like the Atmospheric Model Intercomparison Project (AMIP) or Coupled Model Intercomparison Projects 1-3 (CMIP1-3). This has given a lot of benefits to the global climate modelling community immensely from such coordinated activities. The benefits have been in terms of understanding the process, evaluation of the model and generation of the climate change projections. There have been isolation of the RCD studies which have been always tied to specific targeted interests in research. This has been done to allow for a comprehensive analysis of climate change projections at regional level based on RCD experiments that are not available currently (Giorgi et al., 2009).

The coordinated regional climate downscaling experiment (CORDEX) programme was initiated with an aim of providing a framework for benchmarking for evaluation and possibly improvement of models, on one hand while on the other hand having a set of experiments to provide for exploration to the highest level possible influence of the various sources of uncertainty. CORDEX, therefore, essentially aims at providing a framework for evaluating and benchmarking model performance (model evaluation framework) as well as designing a set of experiments for producing climate projections suitable for utilization in the studies for impact and adaptation within the framework of climate projection (Giorgi et al., 2009).

The framework of climate projection is based on a set of new global model simulations within the CORDEX which were planned to support the IPCC Fifth Assessment Report referred to as CMIP5. These simulations are inclusive of various experiments that ranges from the 21st century simulations of new GHG scenarios, dekadal prediction experiments, other experiments such as the carbon cycle and the ones aiming at investigations of individual feedbacks feedback mechanisms (Taylor et al., 2009).

The methodology applied and the results of the 5-member ensemble simulation of the African climate for the period 19502100 through the use of climate modelling system PRECIS carried out over the CORDEX Africa domain suggest that RCM simulations improve the fit to precipitation and temperature observations in most of the African sub-regions. It is also important to note that the range of RCM projections usually differ from the ones from the GCMs in these regions (Bountempo et al., 2014).

\subsection{Impacts of Climate Change}

The past changes in climate have recently caused a lot of impacts on human and natural systems globally. The evidence of impacts as a result of climate change is very strong. This evidence is most comprehensive within the natural systems. On the human systems, some of the impacts have been associated with climate change whose major or minor contribution can be distinguished from other influences (Niang et al, 2014).

Changing precipitation alters hydrological characteristics and this affects water resources in terms of the quantity and quantity. Hydropower will definitely be severely impacted on in future by these changes in climate due to the non-linearity nature of rainfall-runoff process. It has been observed that a reduction in rainfall by $10 \%$ can easily lead to a loss of hydropower generation by between $25 \%$ and $50 \%$. At the same time a temperature rise by few degrees is also capable of substantially increasing evapotranspiration rates leading to severe impact on hydropower as well. Increases in year to year climate variability may well result in lower energy security in general (Droogers et al, 2009).

Observation of rainfall trends in the past has given indications of a general decline of rainfall received in the main rainfall season of March to May also referred to as "Long Rains" and a general increase during October to December in the region (GoK, 2010; Liebmann et al, 2014). The recent studies have shown that the "Short Rains" which normally occur during October to December season is now extending into what has been normally known to be hot and dry period of January to February season. As a result of these changes, drought is becoming more frequent and prolonged in the Long Rains Season.

Climate variability and climate change have the potential to affect the resource potential for hydropower (Kumar et al., 2011). With the changing climate hydropower resource potential could change as a result of; 
a) River flow regime changes caused by climate changes locally in particular precipitation and temperature changes within the river basin resulting in flow characteristics changes such as volume, variability and seasonality that can directly affect the hydropower resource potential.

b) Changes in the frequencies of extreme meteorological events that may lead to increased cost and associated risks for the future planned hydroelectric power projects.

c) Changes in the characteristics of the sediment load resulting from changing hydrology and extreme meteorological events. Most sediments are likely to result in an increased turbine abrasion leading to decreased efficiency. Increased sediments loads may also results in filling up the reservoir at a faster rate leading to decreased live storage, reduced regulation capability and decreased storage services.

There exist various publications for the studies on the impact of climate change on the river flows. These studies mostly used catchment hydrological models that are driven by climate change scenarios. These scenarios are based on the climate model simulations. Downscaling climate data that involves converting global climate model output into the corresponding climate data set in the catchments is always necessary before using any data in the catchment hydrological models. Finding the best methods for downscaling has currently been given high priority in research area whereby downscaling can be both temporal and spatial. (Kumar et al, 2011).

Even though the climate change impact on the hydropower resource potential might sometimes be approximated as comparatively smaller on average at the global or continental scale, regional and local effects are more significantly possible. The factors that determine the hydropower resource potential include topography and hydrological characteristics such as the volume, variability of the flow and runoff seasonal distribution. In addition to depending on both the regional and local scales, an increase in the variability of climate without necessarily any variation in the mean runoff, is still capable of reducing the production of hydropower. This can only be avoided by increasing the reservoir capacity and modification of the operations to make them capable of accounting for the new hydrological conditions resulting from climate change.

\section{Data and Methods}

The study utilized the meteorological data for at least 30 years period. The data required included rainfall and temperature that were obtained from Kenya Meteorological Department (KMD). The river flow and energy generation data were collected from Water Resources Authority (WRA) and Kenya Electricity Generating Company (KenGen) respectively.

Excel spreadsheet was used to analyze the trend of observed data from Kenya Meteorological department and Water Resources Authority. Climate models are the primary tools available for investigating the response of the climate system to various forcings, for making climate predictions on seasonal to decadal time scales and for making projections of future climate over the coming century and beyond.

CORDEX projected climate scenarios were used to compare with the present trends to be able to determine the current status of climate change over the Sondu Miriu basin. The CORDEX projections were used due to their improved fit to observations of precipitation and temperature in most of the African sub regions. The spatial presentation of these projections were done using QGis application software.

GeoCLIM program was also used in the analysis for the climate data obtained from. GeoCLIM program is part of a set of agroclimatic analysis products developed by the FEWS NT/United States Geological Survey (USGS). The program is designed for climatological analysis of rainfall, temperature and evapotranspiration data. GeoCLIM uses Climate Hazard Group InfraRed Precipitation with Stations (CHIRPS) data sets in raster format.

GeoCLIM tools include settings, data management and analysis. GeoCLIM archives consist of compressed file containing data for a given climatic variable and specific information that could be imported into the GeoCLIM. This makes data sets available for analysis. The GeoCLIM data used for this analysis was from a period between January 1981 and December 2016. The analysis was restricted within Sondu Miriu Basin.

Trend analysis was performed on the river flow and energy generation data to be able to determine the changes related to climate change and magnitudes. This was done through the excel spread sheets.

\section{Results and Discussions}

Based on the historical data for the last 36 years i.e. from 1981 to 2016, there has been increasing trend in annual precipitation in most parts of the basin with some areas recording even more than $200 \mathrm{~mm} /$ dekad. The increasing trend is strongest in the middle of the basin as shown in figure 2 . 


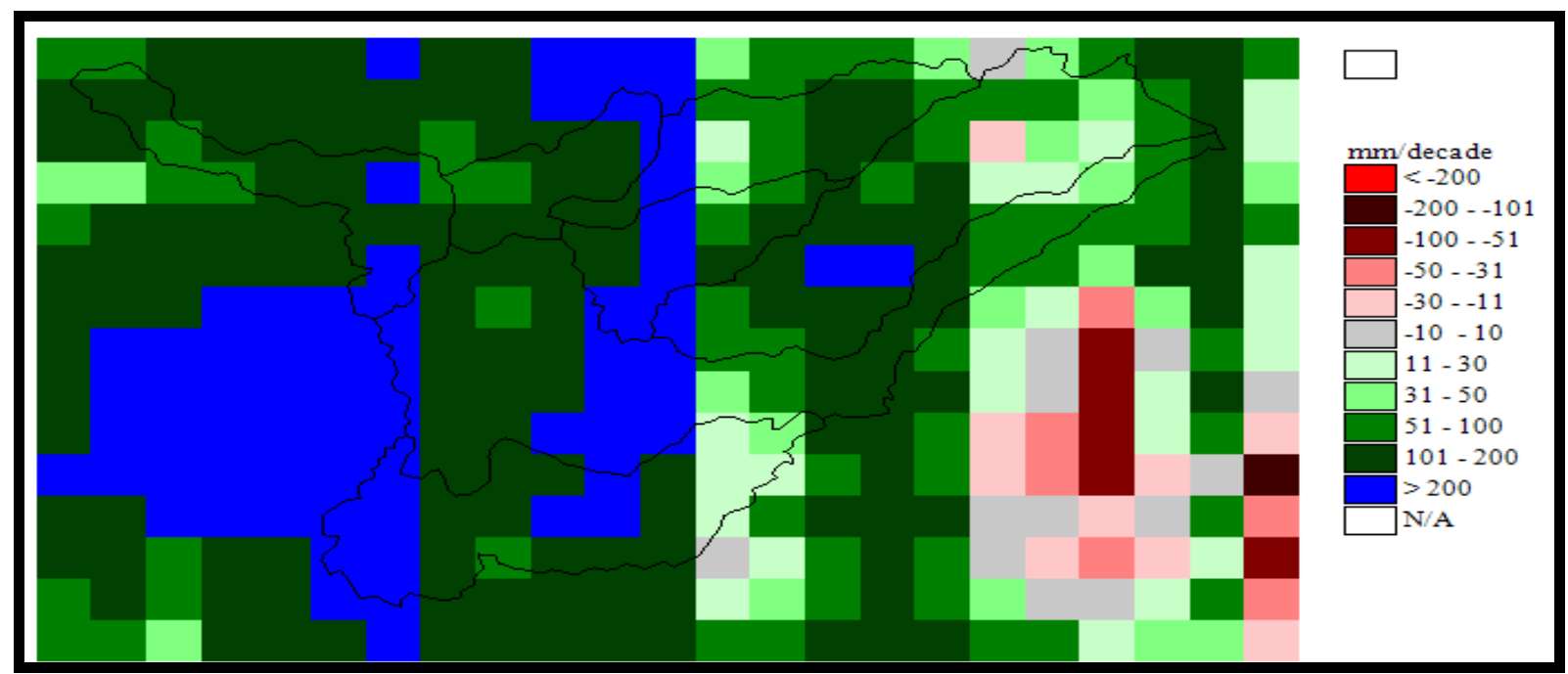

Figure 2: Annual Rainfall Trends

The March-April-May seasonal trends also indicate an increase in precipitation in the whole basin of varing magnitudes ranging from $11 \mathrm{~mm} /$ dekad to $200 \mathrm{~m} /$ dekad as shown in figure 3 . This is usually the long rainfall season in Sondu Basin. During this season the increasing trend is more to the northern part of the basin then the rest. This increase is towards Mau complex areas.

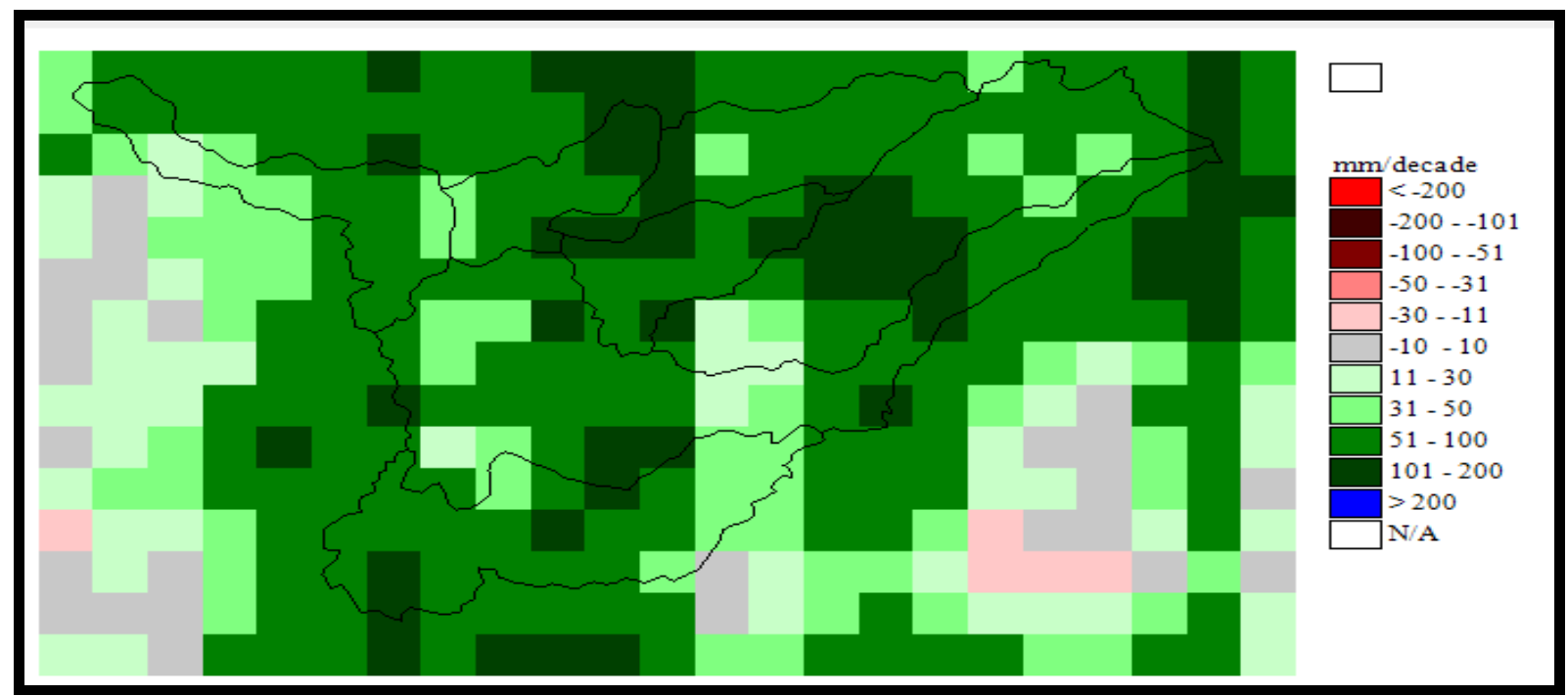

Figure 3: March-April-May Season Rainfall Trends

The June-July-August season is usually a dry period characterized by less rainfall. The results of the analysis indicates there is generally an increasing trend in precipitation in Sondu Miriu basin. The increase in precipitation is more in the southern part of the basin as indicated in figure 4 . 


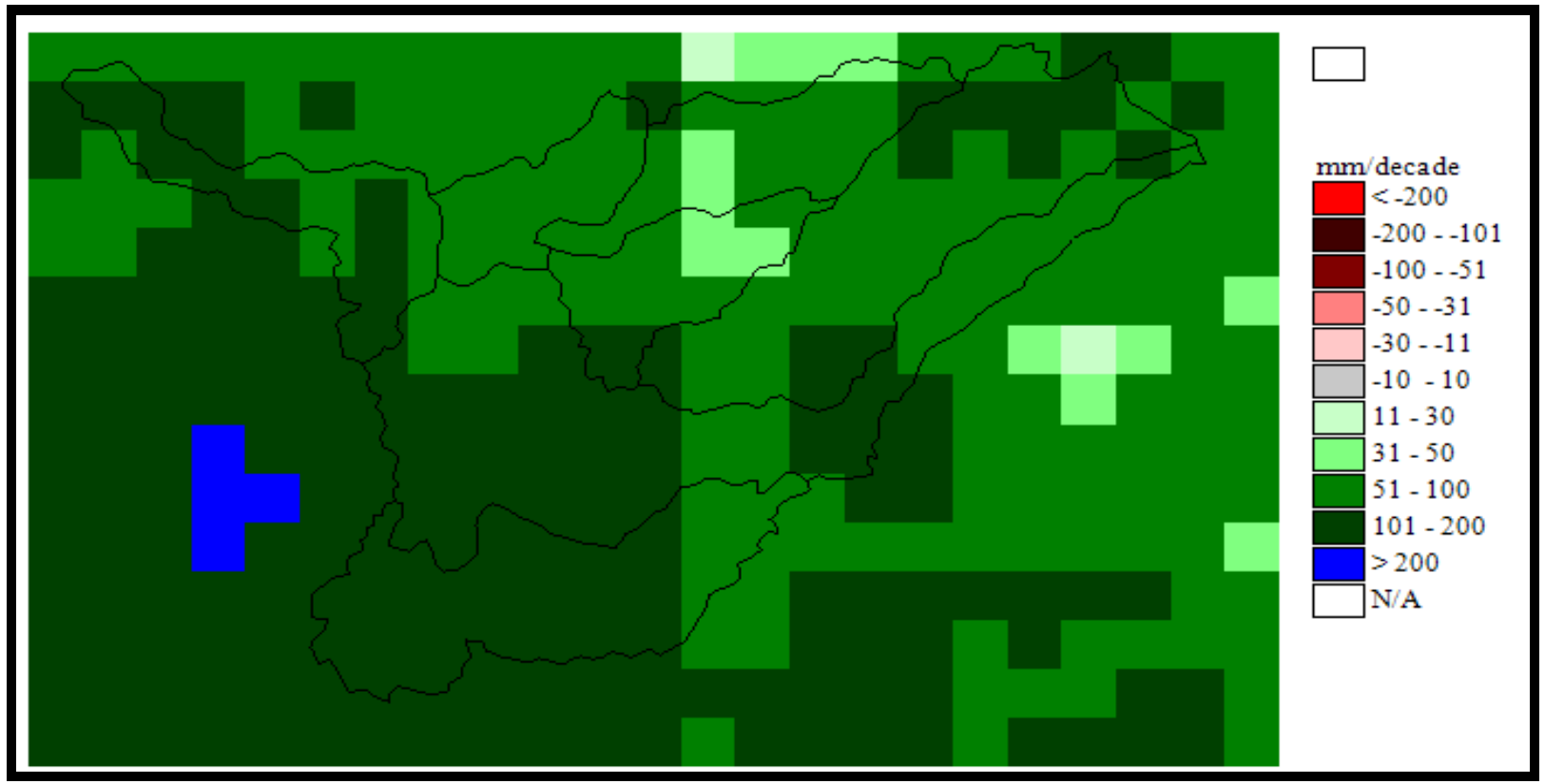

Figure 4: June-July-August Season Rainfall Trends

September-October-November-December marks the short rainfall season in Sondu Miriu basin. During this season, there is a decreasing precipitation trend in the north eastern part of the basin while the middle and southern parts are characterized by increasing precipitation trend as shown in figure 5.

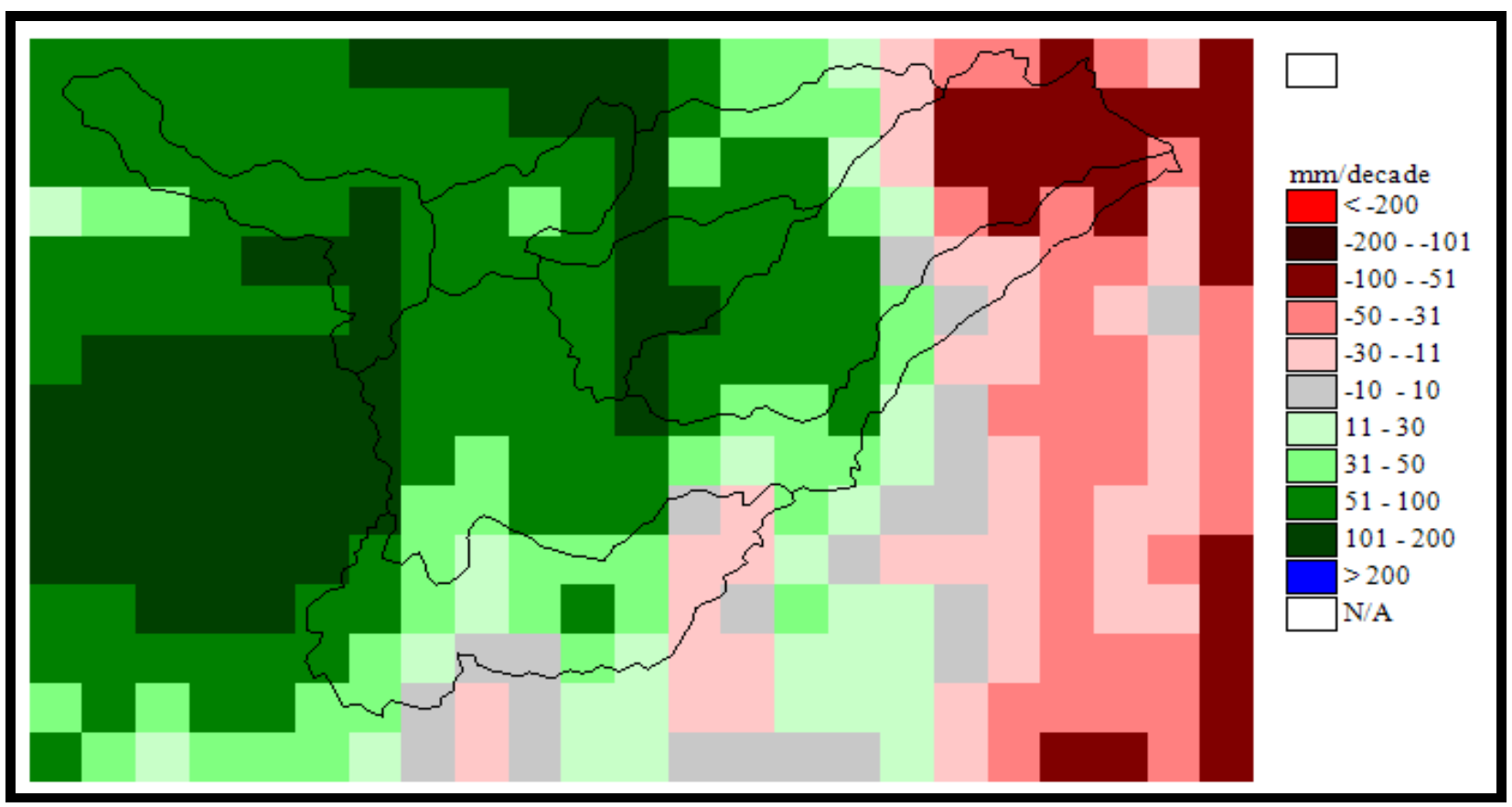

Figure 5: September-October-November-December Season Rainfall Trends

January-February season marks the driest season in the year in this basin. From the climate analysis, there is general decreasing trend in precipitation in the whole basin with the highest decrease recorded in the northern part of the basin as shown in figure 6. 


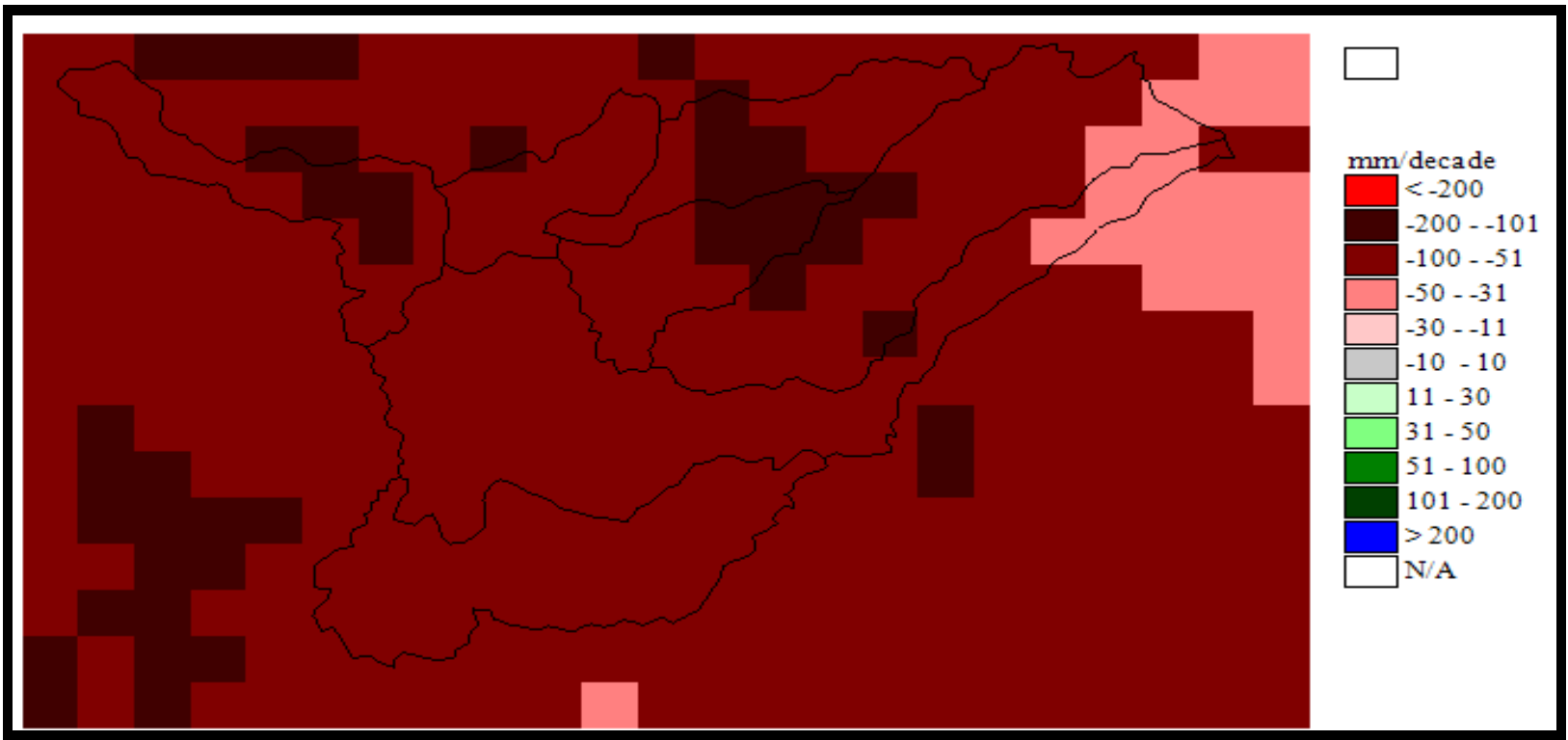

Figure 6: January-February Season

The energy output for Sondu Miriu and Sangoro hydroelectric power plants have however displayed an increasing trend as shown in figure 7 and 8. This is an indication that Sondu Miriu River basin is suitable for hydropower energy generation even in the future.

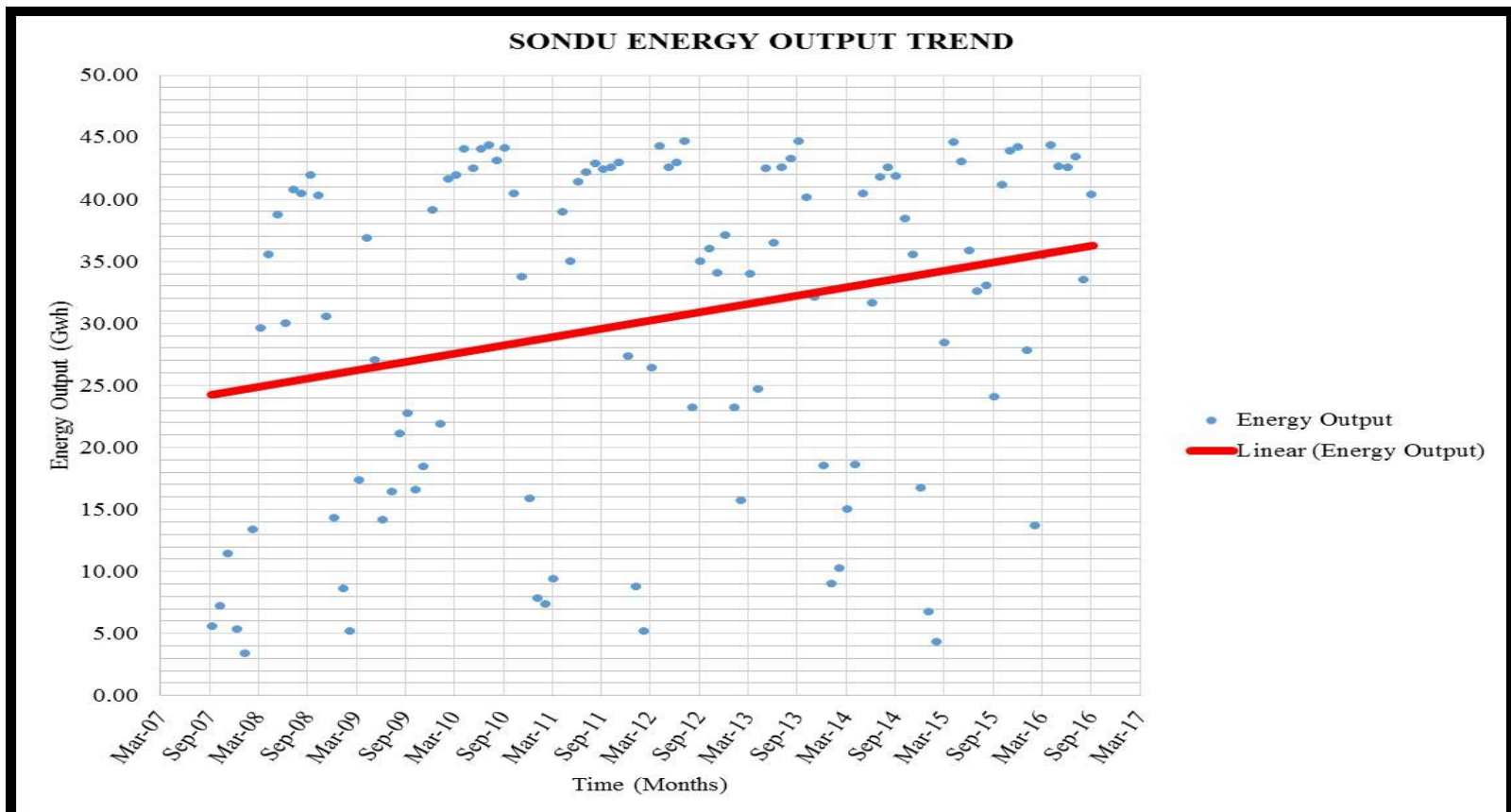

Figure 7: Sondu HEP Energy Output Trend 


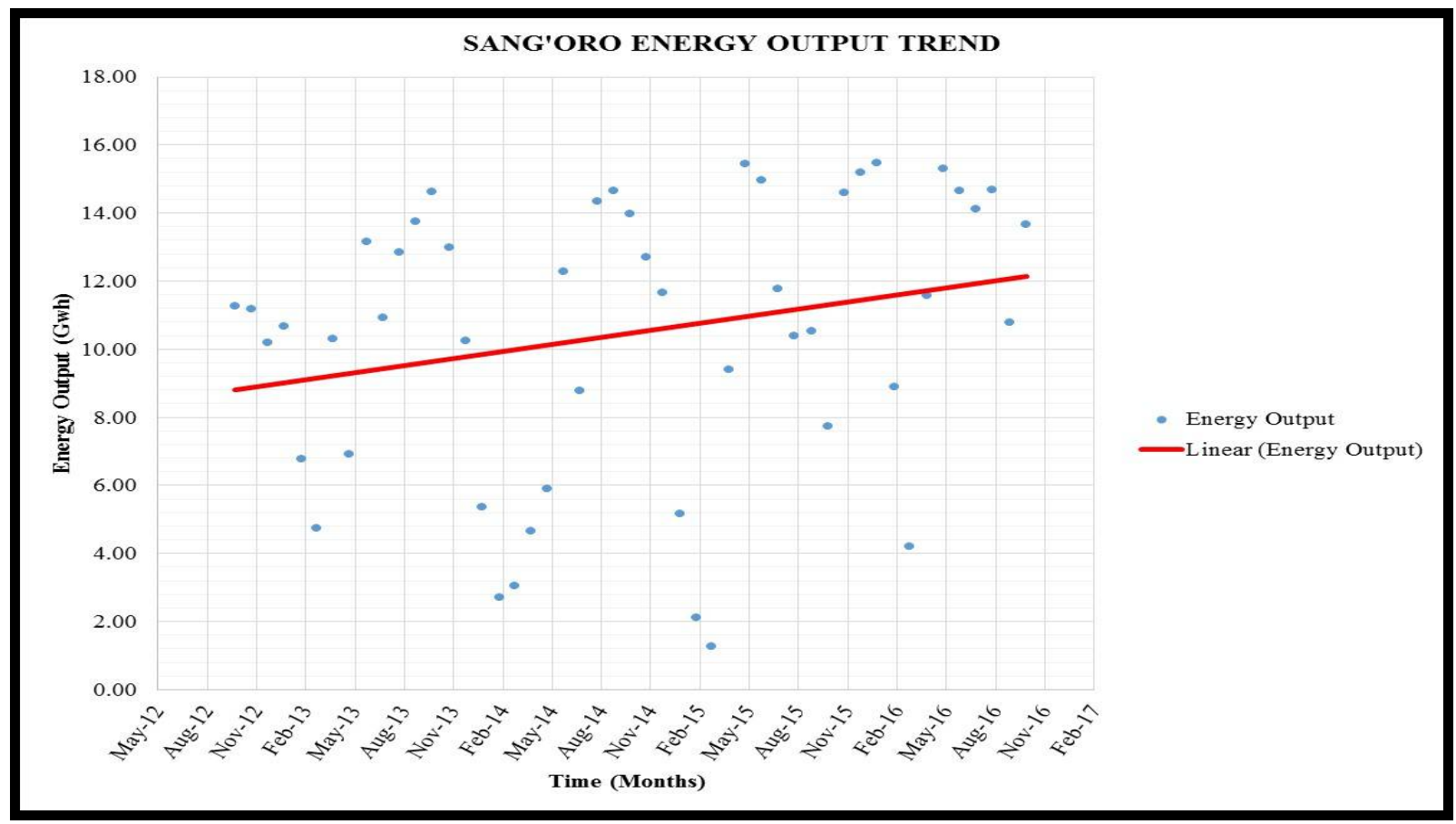

Figure 8: Sang'oro HEP Energy Output Trend

\section{Conclusions and Recommendations}

\subsection{Conclusion}

The climate has been changing within the Sondu Miriu River basin. It has been demonstrated by the rainfall trends in various seasons with an exception of the January-February season that the rainfall trends are positive across the Sondu Miriu River Basin. The energy output from the two existing hydro-electric power plants in the basin namely Sondu and Sang'oro have displayed positive trends. This is an indication that the basin is suitable for the hydropower production even in the future.

\subsection{Recommendations}

Interventions will be required to manage these changes in order to minimize any negative impact the climate change may have on the hydropower energy production in the existing hydropower plants and any future hydropower plants that may be planned in the basin.

\section{References}

i. $\quad$ Budyko, M.I. (1969). The effect of solar radiation variations on the climate of the earth. tellus, 21(5), pp.611-619.

ii. Buontempo, C., Williams, K., McSweeney, C., Jones, R., Mathison, C. and Wang, C. (2014), May. Downscaling a perturbed physics ensemble over the CORDEX Africa domain. In EGU General Assembly Conference Abstracts (Vol. 16).

iii. Claussen, M., Mysak, L., Weaver, A., Crucifix, M., Fichefet, T., Loutre, M.F., Weber, S., Alcamo, J., Alexeev, V., Berger, A. and Calov, R. (2002). Earth system models of intermediate complexity: closing the gap in the spectrum of climate system models. Climate Dynamics, 18(7), pp.579-586.

iv. Collins, W.D., Bitz, C.M., Blackmon, M.L., Bonan, G.B., Bretherton, C.S., Carton, J.A., Chang, P., Doney, S.C., Hack, J.J., Henderson, T.B. and Kiehl, J.T. (2006). The community climate system model version 3 (CCSM3). Journal of Climate, 19(11), pp.21222143.

v. Droogers, P., Butterfield, R. and Dyszynski, J. (2009). Climate change and hydropower, impact and adaptation costs: case study Kenya. FutureWater Report, 85.

vi. Flato, G.M. (2011). Earth system models: an overview. Wiley Interdisciplinary Reviews: Climate Change, 2(6), pp.783-800.

vii. Flato, G., J. Marotzke, B. Abiodun, P. Braconnot, S.C. Chou, W. Collins, P. Cox, F. Driouech, S. Emori, V. Eyring, C. Forest, P. Gleckler, E. Guilyardi, C. Jakob, V. Kattsov, C. Reason and M. Rummukainen (2013). Evaluation of Climate Models. In: Climate Change 2013: The Physical Science Basis. Contribution of Working Group I to the Fifth Assessment Report of the Intergovernmental Panel on Climate Change [Stocker, T.F., D. Qin, and G.-K. Plattner, M. Tignor, S.K. Allen, J. Boschung, A. Nauels, Y. Xia, V. Bex and P.M. Midgley (eds.)]. Cambridge University Press, Cambridge, United Kingdom and New York, NY, USA. 
viii. Giorgi, F., Jones, C. and Asrar, G.R. (2009). Addressing climate information needs at the regional level: the CORDEX framework. World Meteorological Organization (WMO) Bulletin, 58(3), p.175.

ix. GoK (2010). National Climate Change Response Strategy

x. Goosse, H., Barriat, P.Y., Lefebvre, W., Loutre, M.F. and Zunz, V. (2010). Introduction to climate dynamics and climate modeling. Online textbook.

xi. Harrison, G.P., Whittington, H.W. and Gundry, S.W. (1998), September. Climate change impacts on hydroelectric power. In Proc Univ Power Eng Conf. (Vol. 1, pp. 391-394).

xii. Held, I.M. (2005). The gap between simulation and understanding in climate modeling. Bulletin of the American Meteorological Society, 86(11), pp.1609-1614.

xiii. Huntingford, C. and Gash, J. (2005). Climate equity for all. Science, 309(5742), pp.1789-1789.

xiv. IPCC (Intergovernmental Panel on Climate Change). (2013). Climate Change 2013: The Physical Science Basis. Contribution of working group I to the fifth assessment report of the intergovernmental panel on climate change (Stocker, T. F., D. Qin, G. K. Plattner, M. Tignor, S. K. Allen, J. Boschung, A. Nauels, Y. Xia, B. Bex, and B. M. Midgley (eds)). Cambridge University Press, Cambridge, United Kingdom and New York, NY, USA, 1535 pp.

xv. Klein, R.J.T., S.E.H. Eriksen, L.O. Naess, A. Hammill, T.M. Tanner, C. Robledo, and K.L. O’Brien (2007). Portfolio screening to support the mainstreaming of adaptation to climate change into development assistance. Climatic Change, 84(1), pp. 23-44.

xvi. Kumar, A., Schei, T., Ahenkorah, A., Caceres Rodriguez, R., Devernay, J.M., Freitas, M., Hall, D., Killingtveit, A. and Liu, Z. (2011). Hydropower. IPCC special report on renewable energy sources and climate change mitigation, pp.437-496.

xvii. Kusunoki, S., Mizuta, R. and Matsueda, M. (2011). Future changes in the East Asian rain band projected by global atmospheric models with 20-km and 60-km grid size. Climate Dynamics, 37(11-12), pp.2481-2493.

xviii. Liebmann, B., Hoerling, M.P., Funk, C., Bladé, I., Dole, R.M., Allured, D., Quan, X., Pegion, P. and Eischeid, J.K. (2014). Understanding recent Eastern Horn of Africa rainfall variability and change. Journal of Climate, 27(23), pp.8630-8645.

xix. Lin, Y., Donner, L.J., Petch, J., Bechtold, P., Boyle, J., Klein, S.A., Komori, T., Wapler, K., Willett, M., Xie, X. and Zhao, M. (2012). TWP-ICE global atmospheric model intercomparison: Convection responsiveness and resolution impact. Journal of Geophysical Research: Atmospheres, 117(D9).

xx. $\quad$ Masese, F.O., Mwasi, B.N., Etiegni, L. and Raburu, P.O. (2012). Effects of deforestation on water resources: Integrating science and community perspectives in the Sondu-Miriu River Basin, Kenya. INTECH Open Access Publisher.

xxi. Matsueda, M., Mizuta, R. and Kusunoki, S. (2009). Future change in wintertime atmospheric blocking simulated using a 20-km-mesh atmospheric global circulation model. Journal of Geophysical Research: Atmospheres, 114(D12).

xxii. Matsueda, M., Endo, H. and Mizuta, R. (2010). Future change in Southern Hemisphere summertime and wintertime atmospheric blockings simulated using a 20-km-mesh AGCM. Geophysical Research Letters, 37(2).

xxiii. Mizuta, R., Yoshimura, H., Murakami, H., Matsueda, M., Endo, H., Ose, T., Kamiguchi, K., Hosaka, M., Sugi, M., Yukimoto, S. and Kusunoki, S. (2012). Climate simulations using MRI-AGCM3. 2 with 20-km grid. Meteorol. Soc. Jpn.,90(0), pp.233-258.

xxiv. Moomaw, W., F. Yamba, M. Kamimoto, L. Maurice, J. Nyboer, K. Urama, T. Weir (2011). Introduction. IPCC Special Report on Renewable Energy Sources and Climate Change Mitigation [O. Edenhofer, R. Pichs-Madruga, Y. Sokona, K. Seyboth, P. Matschoss, S. Kadner, T. Zwickel, P. Eickemeier, G. Hansen, S. Schlomer, C.von Stechow (eds)], Cambridge University Press, Cambridge, United Kingdom and New York, NY, USA.

xxv. Niang, I., O.C. Ruppel, M.A. Abdrabo, A. Essel, C. Lennard, J. Padgham, and P. Urquhart (2014). Africa. In: Climate Change 2014: Impacts, Adaptation, and Vulnerability. Part B: Regional Aspects. Contribution of Working Group II to the Fifth Assessment Report of the Intergovernmental Panel on Climate Change [Barros, V.R., C.B. Field, D.J. Dokken, M.D. Mastrandrea, K.J. Mach, T.E. Bilir, M. Chatterjee, K.L. Ebi, Y.O. Estrada, R.C. Genova, B. Girma, E.S. Kissel, A.N. Levy, S. MacCracken, P.R. Mastrandrea, and L.L. White (eds.)]. Cambridge University Press, Cambridge, United Kingdom and New York, NY, USA, pp.1199-1265.

xxvi. Petoukhov, V., Claussen, M., Berger, A., Crucifix, M., Eby, M., Eliseev, A.V., Fichefet, T., Ganopolski, A., Goosse, H., Kamenkovich, I. and Mokhov, I.I. (2005). EMIC Intercomparison Project (EMIP-CO2): comparative analysis of EMIC simulations of climate, and of equilibrium and transient responses to atmospheric $\mathrm{CO}_{2}$ doubling. Climate Dynamics, 25(4), pp.363-385.

xxvii. Sellers, W.D. (1969). A global climatic model based on the energy balance of the earth-atmosphere system. Journal of Applied Meteorology, 8(3), pp.392-400.

xxviii. Taylor, K.E. (2009). A summary of the CMIP5 experiment design.http://cmip-pcmdi. llnl. gov/ cmip5/ docs/ Taylor CMIP5 design. pdf.

xxix. WCD (2000). Dams and Development: A New Framework for Decision-Making: The Report of the World Commission on Dams. World Commission on Dams, Earthscan, London, UK.

xxx. Zhao, M., Held, I.M., Lin, S.J. and Vecchi, GA. (2009). Simulations of global hurricane climatology, interannual variability, and response to global warming using a 50-km resolution GCM. Journal of Climate, 22(24), pp.6653-6678.

xxxi. Zhao, M., Held, I.M. and Lin, S.J. (2012). Some counterintuitive dependencies of tropical cyclone frequency on parameters in a GCM. Journal of the Atmospheric Sciences, 69(7), pp.2272-2283. 